Revista Brasileira de Agricultura Irrigada v.11, nº.6, p. 1845 - 1853, 2017

ISSN 1982-7679 (On-line)

Fortaleza, CE, INOVAGRI - http://www.inovagri.org.br

DOI: $10.7127 /$ rbai.v11n600635

Protocolo 635.17 - 19/03/2017 Aprovado em 26/04/2017

\title{
ATRIBUTOS QUÍMICOS DE UM CAMBISSOLO HÁPLICO FERTIRRIGADO COM EFLUENTE DOMÉSTICO
}

Raniere Barbosa de Lira ${ }^{1}$, Miguel Ferreira Neto ${ }^{2}$, José Francismar de Medeiros ${ }^{2}$, Nildo da Silva Dias ${ }^{2}$, Raimundo Fernandes de Brito ${ }^{1}$, Líssia Letícia de Paiva Oliveira ${ }^{3}$

\section{RESUMO}

O uso de efluente doméstico na irrigação é uma alternativa à escassez hídrica nas regiões áridas e semiáridas, mas se faz necessário conhecer os efeitos dessa água residuária no solo, para evitar sua contaminação e de mananciais subterrâneos. Foram investigados nesta pesquisa os efeitos da solução de fertirrigação com efluente doméstico e da mistura de efluente com água de poço sob os atributos físico-químicos de um Cambissolo Háplico cultivado com três cultivares de sorgo. O delineamento experimental foi o de blocos casualizados em parcelas subdividida, com seis repetições. Os tratamentos foram: 3 fontes hídricas (água de poço - controle; água de esgoto doméstico tratado e a mistura de 50\% água de poço $+50 \%$ esgoto doméstico tratado) e três diferentes cultivares de sorgo (IPA 2502, BRS 506 e BRS Ponta Negra). O efluente de esgoto doméstico pode ser utilizado na irrigação do sorgo se rigorosamente manejado. A água de esgoto doméstico em pesquisas para fins agronômicos deve ser aplicada de forma racional, monitorando-se principalmente, a correção da deficiência de fósforo disponível e a elevação do teor de sódio da água aplicada ao solo.

Palavras-chave: recursos hídricos, reuso de água, solução nutritiva

\section{CHEMICAL ATTRIBUTES OF CAMBISOL FERTIRRIGATED WITH SEWAGE EFFLUENT}

\footnotetext{
ABSTRACT

Domestic sewage effluent for irrigation is an option to shortage of water in arid and semiarid zones, but necessitates knowing your effects on soil to avoid contamination of lands and underground springs. The effects of irrigation solution with domestic sewage effluent or

${ }^{1}$ Engenheiros Agrônomos, Cooperativa de Assessoria de Serviços/Coopervida, Mossoró, RN, Brasil. E-mail: ranierebarbosa@bol.com.br; raiferbrirn@hotmail.com

2 Engenheiros Agrônomos, Professores Doutores da Universidade Federal Rural do Semi-Árido/UERSA, Departamento de Ciências Ambientais e Tecnológicas, Av. Francisco Mota, 572 - Costa e Silva, 59625-900, Mossoró, RN, Brasil..E-mail: miguel@ufersa.edu.br; jfmedeir@ufersa.edu.br; nildo@ufersa.edu.br

${ }^{3}$ Doutoranda, Universidade Federal Rural do Semi-Árido/UERSA, Programa de Pós-Graduação em Manejo de Solo e Água, Av. Francisco Mota, 572 - Costa e Silva, 59625-900, Mossoró, RN, Brasil. E-mail: leticia_lissia@hotmail.com
} 
sewage blended with well water on physical-chemical attributes of a Cambisol cultivated with three sorghum cultivars were investigated. The experimental design consisted of randomized block in sub-plot, with six replications. The fertirrigation solution treatments consisted of 3 water sources (well water - control, treated domestic sewage and blended of $50 \%$ well water + $50 \%$ treated domestic sewage). The three water sources were applied at three different sorghum cultivars (IPA 2502, BRS 506 e BRS Ponta Negra). The domestic sewage effluent can be used for irrigation of sorghum plant if carefully monitored. Domestic sewage in research for agronomic purposes should be applied rational manner, mainly monitoring the correction of the available phosphorus deficiency and the increase of the sodium content of the water applied to the soil.

Keywords: water resources, water reuse, nutrients solution.

\section{INTRODUÇÃO}

No nordeste do Brasil, predominantemente semiárido, a escassez de água superficial de boa qualidade dificuldade a prática da agricultura irrigada, inviabilizando o cultivo intensivo com maiores produtividades. A maior parte da região nordeste sofre com o balanço hídrico deficiente, especialmente nos meses de baixas precipitações. Prevê-se que a escassez de recursos hídricos nesta região se torne mais grave nos próximos anos, principalmente, devido ao crescente consumo de água na atividade agrícola e as alterações climáticas.

Os desafios dos agricultores nesta região é a busca por fontes alternativas de água para a irrigação e, deste modo, o uso de efluentes de esgoto de origem doméstica para fins agrícolas é reconhecidamente uma fonte hídrica e nutricional (NOBRE et al., 2010).

Vários pesquisadores (ALI et al., 2010; SALEHI et al., 2008) reportaram o uso de efluente de esgoto tratado como fonte hídrica e nutricional em diversas culturas. Entretanto, o uso destas águas residuárias exige a adoção de práticas de manejo adequadas para evitar impactos sobre a contaminação dos solos e, consequentemente a inviabilidades nos rendimentos das culturas (ALI et al., 2010, HASSAN et al., 2002).

Geralmente, os efeitos da utilização de água residuária nas características físicas e químicas do solo são pronunciados apenas depois de longo período de aplicação, pelos atributos que definem sua composição física e química, pelas condições de clima e pelo tipo de solo (NOBRE et al., 2010). Segundo Rattan et al. (2005), a utilização de água residuária na agricultura pode influenciar de diversas maneiras nas propriedades químicas do solo, como: redução do $\mathrm{pH}$ devido a produção de ácidos orgânicos e $\mathrm{CO}_{2}$; acréscimo nos teores relativos de sódio e da condutividade elétrica do solo, acarretando problemas na estrutura física do solo e, ainda, aumento nos teores de macronutrientes no solo via aplicação de efluente de esgoto a longo prazo.

Dessa forma, são essenciais o monitoramento e a indicação de técnicas de manejo apropriadas em função de vários aspectos, dentre eles, a composição do efluente e efeitos sobre os atributos químicos do solo. Diante do exposto, torna-se necessário o uso sustentável dos recursos hídricos, estimulando o uso racional da água, principalmente na agricultura irrigada. Nesse sentido, objetivou-se avaliar os efeitos da fertirrigação com efluentes de esgoto doméstico associado à diluições com água de poço sob as propriedades químicas de um Cambissolo Háplico cultivado com três cultivares de sorgo.

\section{MATERIAL E MÉTODOS}

A pesquisa foi desenvolvida na área comunitária do Projeto de Assentamento de Reforma Agrária Milagres, município de Apodi, RN (5³5'19.3” S, 3754'7.9" O e 153 $\mathrm{m})$. De acordo com a classificação de Köppen, o clima predominante na região é do 
tipo BSw'h', caracterizado por ser muito quente, seco e salubre, tendo predominância do clima semiárido, inserido no bioma caatinga. A escolha do Assentamento se deu devido à existência de uma estrutura de saneamento e reutilização das águas residuárias da Estação de Tratamento de Esgoto (ETE).
Foram realizadas amostragens de solo na área experimental em diversos pontos da área, para uma caracterização inicial dos atributos físicos e químicos do solo, na camada de 0-0,20 m (Tabela 1 ). O solo da área experimental foi classificado como Cambissolo Háplico Ta eutrófico (EMBRAPA, 2013).

Tabela 1 - Características químicas do Cambissolo Háplico Ta eutrófico, na profundidade de 0 a 0,20 m utilizado no experimento antes da aplicação da água residuária de origem doméstica, Chapada do Apodi, RN.

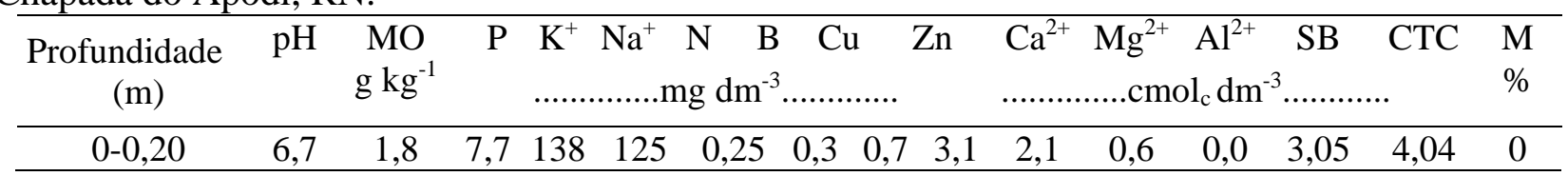

Cada parcela experimental foi constituída de 2 linhas de plantio duplas com dimensões de 20,40 m de comprimento cada uma, sendo 12 sulcos de 2,80 m por linha de plantio e um sulco de $1,80 \mathrm{~m}$ em cada extremidade, constituindo as bordaduras. O preparo do solo se deu por uma gradagem. Os sulcos foram feitos com o auxílio de um sulcador, e os acabamentos foram realizados manualmente com auxílio de enxada.

As plantas de sorgo (Sorghum bicolor L.) foram cultivadas a pleno sol utilizando o delineamento experimental de blocos casualizados em parcelas subdivididas, sendo três fontes hídricas referentes às parcelas $\left(\mathrm{FH}_{1}\right.$ = água de poço - controle, $\mathrm{FH}_{2}$ = água de esgoto doméstico tratado e $\mathrm{FH}_{3}=$ mistura de $50 \%$ água de poço e $50 \%$ de esgoto doméstico tratado) e três cultivares de sorgo referente às subparcelas $\left(\mathrm{C}_{1}=\right.$ IPA 2502, $\mathrm{C}_{2}=\mathrm{BRS} 506 \mathrm{e}$
$\mathrm{C}_{3}=$ BRS Ponta Negra), com seis repetições, totalizando 54 medidas experimentais.

O sistema de plantio adotado foi o de semeadura direta de forma manual, em covas espaçadas de 0,15 m na linha, colocando quatro sementes por covas aproximadamente $0,05 \mathrm{~m}$ de profundidade. Aos 20 dias após semeadura foi realizado desbaste objetivando ajustar a população de plantas, deixando apenas uma por cova, com densidade de 167 mil plantas ha-1.

Adotou-se o sistema de irrigação por sulcos, utilizando-se tubos de polietileno com diâmetro de $20 \mathrm{~mm}$ (3/4"), enterrados a $10 \mathrm{~cm}$ de profundidade, e emissores de microtubos, sistema esse denominado de "Bubbler".

Realizaram-se análises para obter a caracterização físico-química e microbiológica do esgoto doméstico primário e da água do poço artesiano, conforme apresentada na Tabela 2.

Tabela 2 - Características físico-química e microbiológica da água residuária (AR) e da água de poço (AP). Chapada do Apodi, RN.

\begin{tabular}{|c|c|c|}
\hline Características & AR & AP \\
\hline 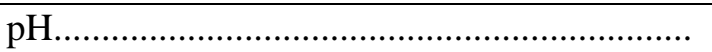 & 7,34 & 6,96 \\
\hline 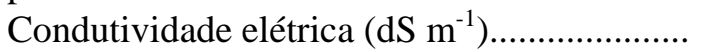 & 1,10 & 0,09 \\
\hline Coliformes termotolerantes (NMP $100 \mathrm{~mL}^{-1}$ ) & $9,8 \times 103$ & 0 \\
\hline Demanda Química de Oxigênio $\left(\mathrm{mg} \mathrm{L}^{-1}\right) \ldots \ldots . .$. & 80 & - \\
\hline Demanda Bioquímica de Oxigênio (mg L L $\left.{ }^{-1}\right)$.. & 27 & - \\
\hline 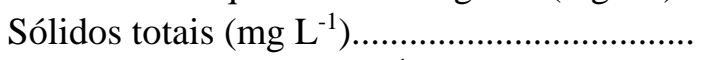 & 655 & - \\
\hline 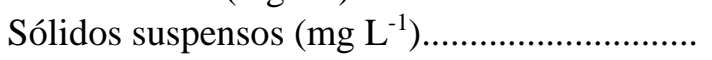 & 44,0 & - \\
\hline 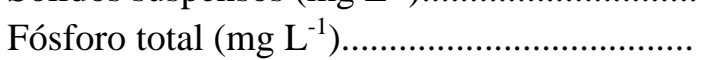 & 7,8 & - \\
\hline
\end{tabular}


Lira et al.

\begin{tabular}{|c|c|c|}
\hline 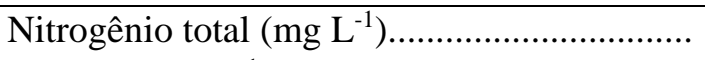 & 54,1 & - \\
\hline 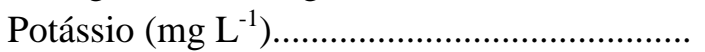 & 23,7 & 11,5 \\
\hline 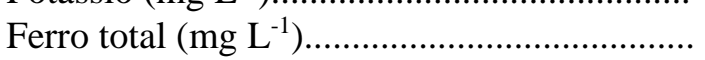 & 0,48 & 0,26 \\
\hline 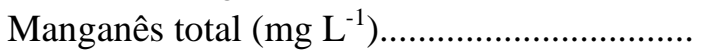 & 0,13 & 0,05 \\
\hline Zinco $\left(\mathrm{mg} \mathrm{L}^{-1}\right) \ldots \ldots$ & 0,08 & 0,2 \\
\hline Cobre $\left(\mathrm{mg} \mathrm{L}^{-1}\right) \ldots \ldots$ & 0,04 & 0,03 \\
\hline 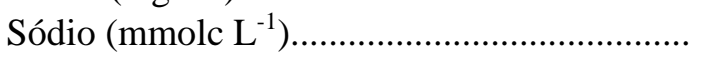 & 7,03 & 0,46 \\
\hline 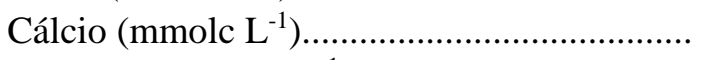 & 1,21 & 0,17 \\
\hline 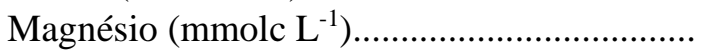 & 0,76 & 0,28 \\
\hline 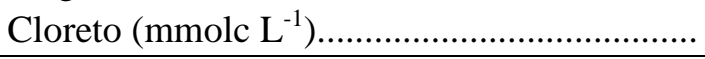 & 2,30 & 0,88 \\
\hline
\end{tabular}

Ao final do experimento coletaram-se amostras compostas com auxílio de trado tipo holandês, na profundidade de 0 a $20 \mathrm{~cm}$, após o corte de todas as plantas. As coletas se deram ao lado do suco, representando as áreas irrigadas, com as três águas, bem como representando nas amostras de solos os ambientes explorados pelas três cultivares de sorgos. Foram realizadas análises de $\mathrm{pH}$, condutividade elétrica, matéria orgânica, potássio, fósforo, cálcio, magnésio, cobre, zinco, ferro e manganês seguindo as recomendações de DONAGEMA (2011). Para cada tratamento foi obtida uma amostra composta resultante da mistura das quatro amostras simples. Em seguida, encaminharam-se as amostras compostas para o Laboratório de Análise de Solo, Água e Planta da Universidade Federal Rural do
Semi-Árido (UFERSA) para se proceder com as análises.

Os dados obtidos foram submetidos inicialmente à análise de variância individual e testes de média no programa estatístico SISVAR® (FERREIRA, 2000). Previamente foram realizados os testes de normalidade dos erros e homogeneidade das variâncias.

\section{RESULTADOS E DISCUSSÃO}

De acordo com a análise de variâncias (Tabela 3), apenas as condutividade elétrica (CE) do solo foi influenciada pelas fontes de água estudadas. Já em relação às cultivares, houve efeito para CE, soma de bases (SB) e capacidade de troca de cátions (CTC).

Tabela 3 - Resumo das análises de variância para as variáveis $\mathrm{pH}$, Condutividade Elétrica (CE), dS $\mathrm{m}^{-1}$ ), Potássio (K), Cálcio (Ca), Magnésio (Mg), Soma de Bases (SB), Capacidade de Troca de Cátions (CTC) e Porcentagem de Sódio Trocáveis (PST) do solo cultivado com três cultivares de Sorgo. Mossoró-RN.

\begin{tabular}{|c|c|c|c|c|c|c|c|c|c|}
\hline \multirow{2}{*}{ FV } & \multirow{2}{*}{ GL } & \multicolumn{8}{|c|}{ Quadrados Médios } \\
\hline & & $\mathrm{pH}$ & $\mathrm{CE}$ & $\mathrm{K}^{+}$ & $\mathrm{Ca}^{2+}$ & $\mathrm{Mg}^{2+}$ & SB & СTC & PST \\
\hline Blocos & 5 & $0,35^{\mathrm{ns}}$ & $0,01^{\mathrm{ns}}$ & $1.943,33^{\mathrm{ns}}$ & $1,06^{* *}$ & $1,31^{\mathrm{ns}}$ & $2,08^{\mathrm{ns}}$ & $2,08^{\mathrm{ns}}$ & $7,8^{\text {ns }}$ \\
\hline Águas (A) & 2 & $0,06^{\mathrm{ns}}$ & $0,12^{*}$ & $394,80^{\mathrm{ns}}$ & $0,28^{\mathrm{ns}}$ & $0,98^{\mathrm{ns}}$ & $0,17^{\mathrm{ns}}$ & $0,17^{\mathrm{ns}}$ & $38,2^{\mathrm{ns}}$ \\
\hline Resíduo a & 10 & 0,11 & 0,02 & 589,51 & 0,13 & 0,75 & 2,93 & 2,93 & 12,3 \\
\hline Cultivares (C) & 2 & $0,18^{\text {ns }}$ & $0,03^{*}$ & $1.759,81^{\mathrm{ns}}$ & $0,29^{\text {ns }}$ & $4,80^{* *}$ & $8,54^{*}$ & $8,54^{* *}$ & $6,0^{\mathrm{ns}}$ \\
\hline$A \times C$ & 4 & $0,02^{\mathrm{ns}}$ & $0,01^{\mathrm{ns}}$ & $388,01^{\mathrm{ns}}$ & $0,12^{\mathrm{ns}}$ & $1,57^{*}$ & 0,69 ns & $0,69^{\text {ns }}$ & $5,0^{\mathrm{ns}}$ \\
\hline
\end{tabular}


ATRIBUTOS QUÍMICOS DE UM CAMBISSOLO HÁPLICO FERTIRRIGADO COM EFLUENTE DOMÉSTICO

\begin{tabular}{|c|c|c|c|c|c|c|c|c|c|}
\hline Resíduo b & 30 & 0,09 & 0,01 & 719,32 & 0,26 & 0,55 & 1,75 & 1,75 & 4,1 \\
\hline$C V_{\text {parcelas }}(\%)$ & & 4,7 & 29,8 & 25,1 & 13,2 & 39,3 & 33,4 & 33,4 & 101,5 \\
\hline CV subparcelas (\%) & & 4,3 & 18,5 & 27,8 & 18,9 & 33,6 & 25,8 & 25,8 & 59 \\
\hline Média geral & & 7,04 & 0,45 & 96,67 & 2,73 & 2,2 & 5,13 & 5,13 & 3,49 \\
\hline
\end{tabular}

As cultivares não influenciou o solo em relação à CE (Tabela 4), embora, na análise de variância, o teste $\mathrm{F}$ tenha indicado diferença. Pode-se inferir que o incremento da CE do solo para a cultura do sorgo não é problema grave, pois está abaixo do limite tolerado pela cultura.

Tabela 4 - Médias ${ }^{1}$ para as variáveis CE, SB e CTC do solo cultivado com três cultivares de sorgo. Mossoró-RN.

\begin{tabular}{lccc}
\hline Cultivares & $\begin{array}{c}\mathrm{CE} \\
(\mathrm{dS} \mathrm{m})^{-1}\end{array}$ & $\begin{array}{c}\mathrm{SB} \\
\left(\mathrm{cmol}_{\mathrm{c}} \mathrm{dm}^{3}\right)\end{array}$ & $\begin{array}{c}\mathrm{CTC} \\
\left(\mathrm{cmol}_{\mathrm{c}} \mathrm{dm}^{3}\right)\end{array}$ \\
\hline BRS 506 & $0,43 \mathrm{~A}$ & $5,06 \mathrm{AB}$ & $5,06 \mathrm{AB}$ \\
IPA & $0,50 \mathrm{~A}$ & $5,85 \mathrm{~A}$ & $5,85 \mathrm{~A}$ \\
Ponta Negra & $0,43 \mathrm{~A}$ & $4,47 \mathrm{~B}$ & $4,47 \mathrm{~B}$ \\
\hline
\end{tabular}

${ }^{1}$ Médias seguidas pela mesma letra na coluna não diferem entre si, a 5\% de probabilidade, pelo teste de Tukey.

Os valores encontrados para a condutividade elétrica das águas (esgoto, mistura e poço atenderam ao padrão de potabilidade previsto na Portaria Ministério da Saúde $n^{\circ}$ 2914/2011 (BRASIL, 2011a), sendo inferior ao limite de $1,57 \mathrm{dS} \mathrm{m}^{-1}$. Além disso, a condutividade elétrica média das águas indicam baixos riscos de obstrução de gotejadores, por ser inferior ao limite de 0,8 dS $\mathrm{m}^{-1}$ (NAKAYAMA et al., 2006). No entanto, alguns cuidados devem ser tomados ao se irrigar sucessivamente com água de esgoto, pois a utilização dessa água ao longo do tempo pode elevar os níveis de CE no solo (SARAIVA; KONIG, 2013).

Constatou-se que as análises apresentaram valores de CE do efluente abaixo do recomendado para uso agrícola de água residuária. Ceará (2002) indica valor médio da condutividade elétrica de água residuária tratada inferior a $3,0 \mathrm{dS} \mathrm{m} \mathrm{m}^{-1}$. Outros autores apresentam resultados que diferem desse estudo, como, por exemplo, Moura et al. (2011) que obtiveram valor de $\mathrm{CE}=1,05$ $\mathrm{dS} \mathrm{m}^{-1}$ em solo fertirrigado com água residuária. Esses resultados também diferem dos obtidos por Fonseca (2001) que estudou as alterações nas características químicas do solo fertirrigado com efluente de esgoto doméstico e constatou um incremento da CE.

As cultivares não influenciaram a CE do solo, mas as variáveis soma de Base (SB) e Capacidade de Troca de Cátions (CTC) do solo indicam que os maiores valores foram proporcionados pela cultivar IPA, enquanto os menores valores foram observados na cultivar Ponta Negra (Tabela 4). Já o solo cultivado com a BRS 506 proporcionou comportamento intermediário para estas características.

A capacidade de troca de cátions (CTC) de um solo, de uma argila ou do húmus representa a quantidade total de cátions retidos à superfície desses materiais em condição permutável $\left(\mathrm{Ca}^{2+}+\mathrm{Mg}^{2+}+\mathrm{K}^{+}+\mathrm{H}^{+}\right.$ $\left.+\mathrm{Al}^{3+}\right)$. A capacidade de troca iônica dos solos representa, portanto, a graduação da capacidade de liberação de vários nutrientes, favorecendo a manutenção da fertilidade por um prolongado período e reduzindo ou 
Lira et al.

evitando a ocorrência de efeitos tóxicos da aplicação de fertilizantes (RONQUIM, 2010).

Analisando a Tabela 4, os teores de CTC encontrados nas cultivares BRS e ponta negra foram estatisticamente diferentes, já a cultivar IPA apresentou valor semelhante a cultivar BRS e diferente estatisticamente da cultivar Ponta Negra. Conforme Ribeiro et al. (1999), a classificação do solo quanto à análise da CTC a pH 7,0 para as cultivares demonstrou resultado dentro da faixa de médio, apesar da aplicação considerável de água residuária. Ressaltando que o solo apresentou baixa CTC a pH 7,0 (4,4 cmolc $\mathrm{dm}^{3}$ ) e observou-se um incremento na CTC quando cultivado com as cultivares de sorgo sendo a IPA a que mais contribui (Tabela 4).

Os teores de fósforo (P) no solo apresentaram diferença para a cultivar BRS quando irrigada com água de poço e água residuária (Tabela 5). Já para cultivar IPA, os teores de $\mathrm{P}$ não deferiram estatisticamente quando a cultivar recebeu a aplicação das águas de mistura e residuária, enquanto que a irrigação com água de poço proporcionou teor de fósforo inferior. Os teores de $\mathrm{P}$ no solo comportaram-se estatisticamente semelhantes para a cultivar Ponta Negra sob a fertirrigação com as três fontes hídricas.

Tabela 5 - Médias ${ }^{1}$ dos teores de fósforo, sódio e magnésio no solo cultivado com três águas de irrigação. Mossoró-RN.

\begin{tabular}{|c|c|c|c|}
\hline \multicolumn{4}{|c|}{ Fósforo (mg dm³ $\left.{ }^{-3}\right)$} \\
\hline \multicolumn{4}{|c|}{ Cultivares } \\
\hline Águas & BRS & IPA & Ponta Negra \\
\hline Poço & 5,67 Аа & $3,47 \mathrm{Bb}$ & $3,51 \mathrm{Ab}$ \\
\hline Mistura & 3,30 Ba & 4,10 Aba & 4,52 Аа \\
\hline Esgoto & 4,22 ABab & 5,64 Аа & 3,32 Ab \\
\hline Média & 4,40 & 4,40 & 3,78 \\
\hline \multicolumn{4}{|c|}{ Sódio (mg dm $\left.{ }^{-3}\right)$} \\
\hline \multicolumn{4}{|c|}{ Cultivares } \\
\hline Águas & BRS & IPA & Ponta Negra \\
\hline Poço & $22,73 \mathrm{Ba}$ & 24,77 Аа & $24,40 \mathrm{Ba}$ \\
\hline Mistura & $71,15 \mathrm{Aa}$ & $35,71 \mathrm{Ab}$ & $21,43 \mathrm{Bb}$ \\
\hline Esgoto & $65,77 \mathrm{Aa}$ & 43,32 Аа & 66,51 Аа \\
\hline Média & 53,22 & 34,60 & 37,45 \\
\hline \multicolumn{4}{|c|}{ Magnésio $\left(\mathrm{cmol}_{\mathrm{c}} \mathrm{dm}^{-3}\right)$} \\
\hline \multicolumn{4}{|c|}{ Cultivares } \\
\hline Águas & BRS & IPA & Ponta Negra \\
\hline Poço & $1,36 \mathrm{Bb}$ & $2,76 \mathrm{Aa}$ & 1,83 Aab \\
\hline Mistura & 1,92 ABa & 2,58 Аа & 2,03 Аа \\
\hline Esgoto & 2,85 Аа & 3,00 Аа & $1,50 \mathrm{Ab}$ \\
\hline Média & 2,04 & 2,78 & 1,79 \\
\hline
\end{tabular}

${ }^{1}$ Em cada característica, médias seguidas pela mesma letra maiúsculas nas colunas e pela mesma letra minúscula nas linhas, não diferem entre si, a 5\% de probabilidade, pelo teste de Tukey. 
O solo apresentou teores de $\mathrm{P}$ estatisticamente diferente entre as cultivares IPA e BRS quando fertirrigado com água de poço, e o valor da média do teor de $\mathrm{P}$ no solo foi estaticamente inferior para a cultivar Ponta Negra $(3,78)$. Para água de mistura, o solo apresentou diferença significativa do $\mathrm{P}$ em todas cultivares, já para água residuária o teor de fósforo foi superior para cultivar IPA, enquanto que as cultivares BRS e Ponta Negra quando irrigadas com água residuária obtiveram médias estatisticamente inferiores com relação ao teor de $\mathrm{P}$ no solo. Para água de mistura, o solo apresentou teor de $\mathrm{P}$ estatisticamente semelhante para todas cultivares, já para água residuária o teor de fósforo foi superior para cultivar IPA, enquanto que as cultivares BRS e Ponta Negra quando irrigadas com água residuária obtiveram médias estatisticamente inferiores com relação ao teor de P no solo (Tabela 5).

Quando se compara esses valores de $\mathrm{P}$ obtidos no final do ciclo $\left(7,7 \mathrm{mg} \mathrm{dm}^{-3}\right)$ com o antes do cultivo, observa-se que houve uma redução do teor de fósforo do solo, provavelmente devido a utilização da água residuária, comportando-se agronomicamente como muito baixo, de acordo com a CFSEMG (1999). Na literatura existem vários relatos de alterações nos teores de fósforo no solo em decorrência da aplicação de águas residuárias, corroborando com os resultados encontrados neste trabalho. Porém, Fonseca (2001) não constatou alteração no teor de fósforo do solo mediante aplicação de água residuária de origem doméstica. Kouraa et al. (2002) explicam que para ocorrer mudanças nas características químicas do solo são necessários vários anos de irrigação, visto que a dinâmica deste ocorre muito lentamente.

Os teores de sódio $\left(\mathrm{Na}^{+}\right)$no solo, quando cultivado com a cultivar BRS, não apresentaram diferença estatística quando receberam aplicação da água de esgoto e de mistura, já quando foi irrigada com água de poço apresentou média de Sódio no solo estatisticamente inferior. Com relação às médias de $\mathrm{Na}^{+}$no solo estas não diferiram estatisticamente quando a cultivar IPA foi irrigada com ambas as águas. Para a cultivar Ponta Negra, o maior teor de sódio no solo ocorreu quando esta cultivar foi irrigada com a água de esgoto e os menores valores, quando o cultivo aconteceu com as águas de poço e de mistura, os quais não diferiram entre si (Tabela 5).

Avaliando as cultivares dentro das águas, de poço e de esgoto verificou-se que ambas não proporcionaram diferenças nos teores de $\mathrm{Na}^{+}$no solo, independentemente da cultivar. Entretanto, para a água de mistura, a cultivar BRS proporcionou valores superiores às outras duas, que não diferiram (Tabela 5). Constatou-se que os maiores teores de $\mathrm{Na}^{+}$no solo foram obtidos no tratamento que utilizava água residuária, a qual fornecia um maior aporte de sódio disponibilizado pela água residuária em relação aos demais tratamentos. Vale ressaltar que o teor de sódio antes do cultivo foi maior e, até ao final do cultivo esses valores foram minimizados.

Os resultados obtidos dos teores de magnésio $\left(\mathrm{Mg}^{+}\right)$no solo, para cultivar BRS, quando irrigada com água de esgoto, apresentou os maiores teores, enquanto os menores teores foram proporcionados pela água de poço. A água de mistura proporcionou comportamento intermediário. As cultivares IPA e Ponta Negra não apresentaram diferença em função das águas de irrigação (Tabela 5). Para a relação cultivares $\mathrm{x}$ águas, notou-se que na água de poço, a cultivar IPA obteve valores superiores de $\mathrm{Mg}^{+}$no solo, enquanto os menores valores foram proporcionados pela cultivar BRS, e a cultivar Ponta Negra apresentou valores intermediários. Na água de mistura, os teores de $\mathrm{Mg}^{+}$não diferiram entre as cultivares. E na água de esgoto, às cultivares BRS e IPA apresentaram valores superiores, e não diferiram ente si (Tabela 5).

Para o magnésio observou-se que ocorreram acréscimos importantes nos seus teores após o cultivo, podendo ser classificados agronomicamente o solo de acordo com CFSEMG (1999), em nível bom 
os que apresentaram teores entre $(0,91$ a 1,50

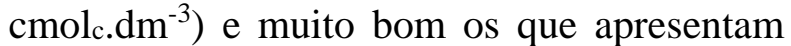
teores superiores a $1,50 \mathrm{cmol}_{\mathrm{c} .} \mathrm{dm}^{-3}$. De acordo com Ricci et al. (2010), os teores de magnésio foram influenciados significativamente pela adição de lodo de esgoto no solo. No trabalho desenvolvido por Erthal et al. (2010), as concentrações de magnésio no solo aumentaram com o tempo de aplicação de água residuária da bovinocultura.

\section{CONCLUSÃO}

Com base nesse experimento foi possível concluir que o efluente de esgoto doméstico pode ser utilizado na irrigação do sorgo se rigorosamente manejado.

A água de esgoto doméstico em pesquisas para fins rurais deve ser aplicada de forma racional, monitorando-se principalmente, a correção da deficiência de fósforo disponível e a elevação do teor de sódio da água aplicada ao solo.

\section{REFERÊNCIAS BIBLIOGRÁFICAS}

ALI, H.M.; EL-MAHROUK, E.M.; HASSAN, F.A.; KHAMIS, M.H.; 2010. Growth, chemical compositions and soil properties of Tipuana speciose irrigated with sewage effluent. Paper presented at the 25th Meeting of Saudi Biological Society, Nanotechnology in Life Sciences, Alasa City at King Faisal University.

BRASIL. Portaria MS $n^{0}$ 2914, de 12 de dezembro de 2011. Dispõe sobre os procedimentos de controle e de vigilância da qualidade da água para consumo humano e seu padrão de potabilidade. Diário Oficial [da] União, Brasília, 2011a. Disponível em: $<$ http://www.cvs.saude.sp.gov.br/zip/Portaria _MS_2914-11.pdf >. Acesso em: 02 jan. 2016.

CEARÁ. Portaria no 154, de 22 de julho de 2002. Dispõe sobre padrões e condições para lançamento de efluentes líquidos gerados por fontes poluidoras. Disponível em: $<$ http://antigo.semace.ce.gov.br/integracao/bi blioteca/legislacao/conteudo_legislacao.asp?c d=95> . Acesso em: 02 mar. 2016.

Comissão de Fertilidade do Solo do Estado de Minas Gerais - CFSEMG. Recomendações para o uso de corretivos e fertilizantes em Minas Gerais - $5^{\text {a }}$ aproximação. Viçosa, MG: 1999.

DONAGEMA, G. K.; CAMPOS, D. V. B.; CALDERANO, S. B.; TEIXEIRA, W. G. \& VIANA, J. H. M. Manual de Métodos de Análise de Solo. 2.ed. Rio de Janeiro: Embrapa Solos, 230p, 2011.

\begin{tabular}{|c|c|}
\hline $\begin{array}{l}\text { EMBRAPA. } \\
\text { Pesquisa }\end{array}$ & $\begin{array}{l}\text { Centro } \\
\text { de }\end{array}$ \\
\hline rasileiro & de \\
\hline
\end{tabular}
Solos. Rio de Janeiro, RJ: Embrapa - Solos, 2013. 412 p.

ERTHAL, V. J. T.; FERREIRA, P. A.; MATOS, A. T. de; PEREIRA, O. G. Alterações físicas e químicas de um Argissolo pela aplicação de água residuária de bovinocultura. Revista Brasileira de Engenharia Agrícola e Ambiental, v.14, n.5, p.467-477, 2010.

FERREIRA, D.F. Sistema de análises de variância para dados balanceados. Lavras: UFLA, 2000. (SISVAR 4. 1).

FONSECA, A. F. Disponibilidade de nitrogênio, alterações nas características químicas do solo e do milho pela aplicação de efluente de esgoto tratado. 2001. 110f. Dissertação (Mestrado), Escola Superior de Agricultura "Luiz de Queiroz”, Universidade de São Paulo, Piracicaba. 2001.

HASSAN, F.A.; EL-JUHANY, L.I.; ELSETTAWY, A.A.; SHEHATA, M.S.; 2002. Effects of irrigation with sewage effluent on the growth of some forest trees species, physical and chemical properties of the soil. Paper presented at the second 
Conference on Sustainable Agricultural Development. Fayoum, Egypt.

KOURAA, A.; FETHI, F.; LAHLOU, A.; OUAZZANII N. Reuse of urban wastewater by combined stabilization pond system en Benslimane (Marocco). Urban Water, v.4, n.4, p.373-378, 2002.

MOURA, F. N.; BATISTA, R. O.; SILVA, J. B. A.; FEITOSA, A. P.; COSTA, M. S. Desempenho de sistema para tratamento e aproveitamento de esgoto doméstico em áreas rurais do semiárido brasileiro. Engenharia Ambiental, v.8, n.1, p.264-276, 2011.

NAKAYAMA, F. S.; BOMAN, B. J.; PITTS, D. Maintenance. In: LAMM, F. R.; AYARS, J. E.; NAKAYAMA, F. S. (Eds.). Microirrigation for crop production: design, operation, and management. Amsterdam: Elsevier, 2006. Cap. 11, p. 389 430.

NASCIMENTO, Flávio R. do. Recursos Naturais e Desenvolvimento Sustentável: Subsídos ao Manejo Geoambiental da Subbacia do Baixo Pacoti - CE. (Dissertação de Mestrado), UECE, Fortaleza, 2003. 154p.

NOBRE, R. G.; GHEYI, H. R.; SOARE, F. A. L.; ANDRADE, L. O.; NASCIMENTO, E. C. S. Produção do girassol sob diferentes lâminas com efluentes domésticos e adubação orgânica. Revista Brasileira de Engenharia Agrícola e Ambiental, v.14, n.14, p.747-754, 2010.

PAGANINI, W.S. Reuso de água na agricultura. In: Mancuso, PCS, Santos HF, editores. Reuso de água. São Paulo: Manole; p. 339-401. 2003.
RATTAN, R. K.; DATTA, S.P.; CHHONKAR, P.K.; SURIBABU, K. \& SINGH, A.K. Long-term impact of irrigation with sewage effluents on heavy metal content in soils, crops and groundwater: a case study. Agriculture, Ecosystems \& Environment, v.109, n.3/4, p.310-322, 2005.

RIBEIRO, A.C.; GUIMARÃES, P.T.G.; ALVAREZ V., V.H. (Ed.). Recomendação para o uso de corretivos e fertilizantes em Minas Gerais: 5a aproximação. Viçosa, MG: Comissão de Fertilidade do Solo do Estado de Minas Gerais, 1999. 359p.

RICCI, A. B.; PADOVANI, V. C. R.; PAULA JÚNIOR, D. R. Uso de lodo de esgoto estabilizado em um solo decapitado: II - Atributos químicos e vegetação. Revista Brasileira de Ciência do Solo, v.34, p.543551, 2010.

RONQUIM, C. C. Conceitos de fertilidade do solo e manejo adequado para as regiões tropicais. Embrapa Monitoramento por Satélite, Campinas, 2010.

SALEHI A.; TABARI M.; MOHAMMADI J.; ALI-ARAB A.R. Effect of irrigation with municipal effluent on soil and growth of pinus eldarica Medw. trees. Iranian Journal of Forest and Poplar Research, v.16, p.186196, 2008.

SARAIVA, V. M.; KONIG, A. Productivity purple-elephant-grass irrigated with treated domestic sewage in the semiarid potiguar and its uses. Holos, v.29, n.1, p.28, 2013.

SILVA, R. R. Avaliação sócio-ambiental do uso de efluente de esgoto tratado na irrigação de culturas no Município de Lins-SP. Tese de Doutorado. Escola Superior de Agricultura "Luiz de Queiroz. 2008. 